\title{
Examination of Control Parameters for Medical Grade Insulin Pump
}

\author{
J. V. Alamelu, A. Mythili
}

\begin{abstract}
In this work, an attempt has been made to identify the appropriate parameters of Permanent Magnet Direct Current (PMDC) motor for infusion pump. PMDC motor plays important role in medical devices. In this, selection of parameters such as rotor inertia, armature resistance, armature inductance and back electro motive force constant is crucial that help to achieve the required speed. The proposed work uses PID controller (Proportional Integral Derivative) and LQG (Linear-Quadratic Gaussian) control algorithm to evaluate the parameters for transient response of the PMDC motor. It is demonstrated that the chosen parameters are able to reach the required speed with quick rise time by 0.691 seconds by employing $L Q G$.
\end{abstract}

Keywords: Permanent Magnet Direct Current; infusion pump; control algorithm; Linear-Quadratic Gaussian; Proportional Integral Derivative.

\section{INTRODUCTION}

Integration of recent trends in computing is prominent in the medical and health care devices. The advent of the invention of bedside, portable medical devices is more which support the patient based on the need. Many treatment needs infusing drug, nutrients to the patient using infusion pumps. The selection of components of the infusion pump, design and obtaining the desired response is mandate. There is a plenty of literature available in the field of infusion pump, insulin pump, devices used, selection of components, prototype design and implementation.

The infusion pumps [1] such as insulin pumps, hospital infusion pumps, ambulatory enteral feeding pumps, home infusion pumps are designed with many devices such as flow sensors, pressure sensors, control valves, pump with gear arrangement and PMDC motors [2]. The electrical, mechanical specifications of the devices are the most important factor that has to be considered for the selection so that the complete medical device is operated precisely, accurately with improved battery life. The medication for the patients as prescribed by the physicians should be accurately administered. The continuous delivery of the fluids as nutrients and medicines ranges from millilitres to litres per hour. The pumping system should be operated accurately and precisely to deliver the fluid as per the prediction [3].

In general, the selection of the motors is based on its reliability, size, and efficiency. Several motors like stepper motors, PMDC, Brushless Direct Current (BLDC) motors are available which is designed by many manufacturers. Among

Revised Manuscript Received on December 01, 2019

* Correspondence Author

Assistant Professor, Dept of EIE, MSRIT, jvalamelu@gmail.com

A. Mythili, Associate Professor, SENSE, VIT, Chennai mythili.asaithambi@vit.ac.in
J. V. Alamelu*, Research scholar, SENSE, VIT, Chennai and

all, PMDC is preferred as it is efficient than BLDC in terms of noise and smooth operation. High-strength customized gearing reduces noise levels for patient comfort during the day and while sleeping. The insulin pump is designed with PMDC motors such as 08GS61, 16DCT depending on different types of infusion pump available. DC motors are also utilized in the docking unit of the artificial pancreas [4].

Numerous surveys on control, stability of PMDC motor are indicated. To obtain steady state, regulated flow, as per the fluid and drug to be infused to the patient through an infusion system [5] accurate modelling, selection of optimized controller and control dynamics [6] is mandatory for a system. Hence the study of PMDC is indeed an important concept. Several control strategies had been developed, among them PID is one of the widely used controllers. The tuning of the gain values of the PID controller [7] can be done using traditional Ziegler Nicholas method, Process reaction curve method. Research is carried out with optimization methods like particle swarm optimization, Genetic Algorithms, fuzzy controller to obtain required speed of DC motor with PID or without PID controller. Apart from the above specified techniques optimal controllers like Linear Quadratic Controller (LQR), model predictive control are also incorporated in diverse field of control applications. To analyse the dynamic response of PMDC motors, the motors are tested with conventional PID for the controller responses and further, the noise is estimated with Kalman filter.

The literature is reported that PID controller with Kalman filter impede good characteristics of the DC motor with noise. Literature reveals that to analyse the system stability or to obtain optimal control before employing the controller strategies adaptively or optimally, placement of poles and zeros has to be analysed for the stability. To incorporate it, pole replacement technique, Lyapunov stability techniques are used along with Kalman filter to inhibit the characteristics of DC motor [8]. In this work, the performance, stability, control is implemented particularly for the Faulhaber 0651 motor series based on the specification provided by the manufacturer [8].

The selection of the motor integrated to the infusion pump is an important aspect in the design. Different types of small and micro motors are available like Brushless DC motor, DC servomotor, stepper motor and PMDC motors to use in medical devices. In infusion pumps, DC based micro motors are preferred over other motors as it provides improved performance in terms of noise reduction, optimal control and cogging. Several manufacturers have designed and prototyped many micro motors for infusion pump devices. In this work, the motor 0615 is considered to obtain the required speed of the DC motor as per the drug flow rate prescribed for the patient [9].

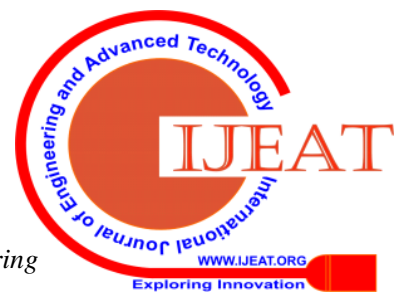


Implementation of a PID control strategy is done with the DC motor specified with load, noise conditions and the device stability is verified.

Motors for medical applications are designed with quality by changing the processes, materials. Value added interfaces are introduced and as a result the performance of the motors is improved. Even though motor hardware is optimized by the several manufacturers, in real time environment optimization and system stability has to be checked. Hence the implementation of different controller strategies and optimal control is needed for the micro motor that is interfaced in an infusion pump system [10].

The motor interfaced with infusion pump system might be susceptible to noise and hence the stable response of the system is obtained by incorporating Kalman filter to estimate and then control the speed of the motor as per the required flow rate that should be infused [11]. In this study, PID control strategy is implemented and verified for the transient response of the motor. For an infusion pump motor quick rise time is needed. Apart from this, the noise induced as measurement or the process noise cannot be filtered or regulated. To achieve these, the DC motor with noise is regulated with LQG that has Kalman filter, measures and predict the result to maintain stable, required transient response is implemented [12]. The output response of the DC motor is analysed. The intention is if the dc motor response is stable, the flow rate will be stable such that the drug will be infused to the patient as per the recommendations of the physician.

\section{SYSTEM DESIGN}

To implement the design, electrical and mechanical parameters the DC motor (PMDC) must be considered to attain the stability of the system with in the required time slot. For the infusion pump's DC motor, the specification of mechanical and electrical parameters of the Faulhaber micro motor is considered [13]. Accordingly, the corresponding transfer function is formulated for a typical closed loop system containing noise with PID controller.

DC Motor Transfer function: Considering the DC motor as a plant the transfer function for the DC motor is modelled. The parameters needed for determining the transfer function of the $\mathrm{DC}$ motor are $\mathrm{R}_{\mathrm{a}}$ : Armature resistance, $\mathrm{L}_{\mathrm{a}}$ : Armature inductance, $\mathrm{i}_{\mathrm{a}}$ : Armature current, $\mathrm{i}_{\mathrm{f}}$ : Field current, $\mathrm{e}_{\mathrm{a}}$ : Input voltage, $\mathrm{e}_{\mathrm{b}}$ : Back electromotive force (emf), $\mathrm{T}_{\mathrm{m}}$ : Motor torque, $\omega$ : An angular velocity of rotor, J: Rotating inertial measurement of motor bearing, $\mathrm{K}_{\mathrm{b}}$ : emf constant, $\mathrm{K}_{\mathrm{T}}$ : Torque constant, B: Friction constant,

Based on this the transfer function for the given plant system, DC motor is given as

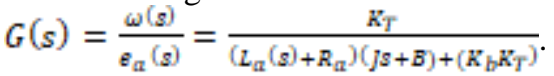

The DC motor is analysed for the transient response with PID controller as a closed loop system is shown in the Fig.1. PID controller is a conventional controller used in many process control applications to obtain stable response output from a given process plant. Here the process plant is considered as PMDC motor which is of brushed micro DC motor type. In most of the medical equipment, micro motors are preferred. The transient response of such motor has to be analysed.

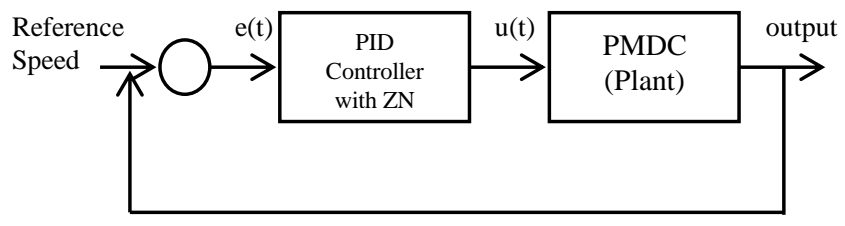

Fig. 1. PID controller with DC motor

The mathematical representations of the PID controller are given below.

$$
u(t)=K_{p} e(t)+K i \int_{0}^{t} e(\tau) d(\tau)+K_{d} \frac{d e(t)}{d t}
$$

where $u(t)$ is the output of PID controller, e(t) is error, $K_{p}, K_{i}$,

$\mathrm{K}_{\mathrm{d}}$ are the controller gains which is obtained in this work

using Z-N method with different iterations [14]. Large number of values is provided to the tuning method. Here the tuning of the gain values are done based on basic NN tool and

those values are fed to the PID controller and the stable transient response for the plant model is obtained.

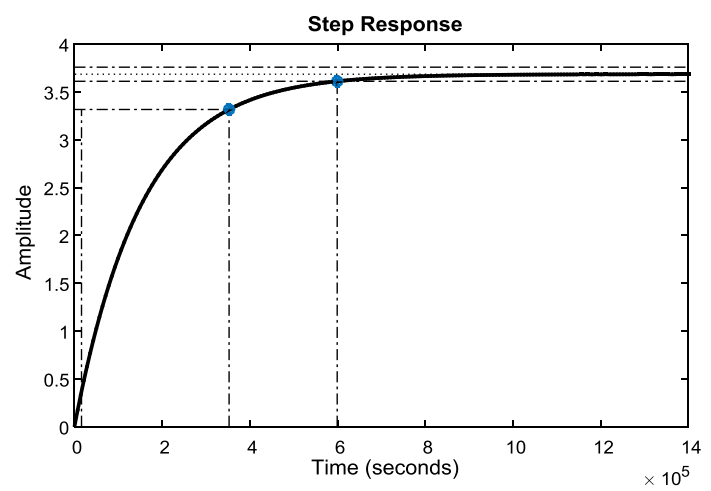

Fig.2. Transient response with PID

The response obtained is shown in Fig. 2. From the response it is observed, the settling time $t_{\mathrm{s}}$ is $5.99 \times 10^{5}$ seconds and the rise time $\mathrm{t}_{\mathrm{r}}$ is $3.37 \times 10^{5}$ seconds.

In practical situations of the infusion pump system the motor housed on the unit might undergo changes because of the noise. The noise on the system may affect performance of the transient response which in turn affects the speed of the motor. If the speed is affected, the flow of the drug and the nutrients to be infused will not be optimal which affect the patients' health condition. The flow rate should be optimum and quick rise time is the objective of tuning of the controller [15]

To verify this aspect, noise which is a white Gaussian noise is added to the system and it is regulated using Linear Quadratic Gaussian (LQG) [16] is a state space technique which is used as optimal regulators. This technique is effective where ever noise and disturbances are included in the system. In practical situation, no system exists without process and measurement noise. LQG utilizes Kalman filter to estimate the state of the system and noise. The block diagram of the DC motor with LQG is shown in Fig.3. In the block diagram it is clear that the DC motor considered for the infusion pump is the plant. For the motor, $y$ is the output which is dependent on LQG regulator values; $w$ and $v$ are the external disturbances which are driven by the controller or regulator $u$. 


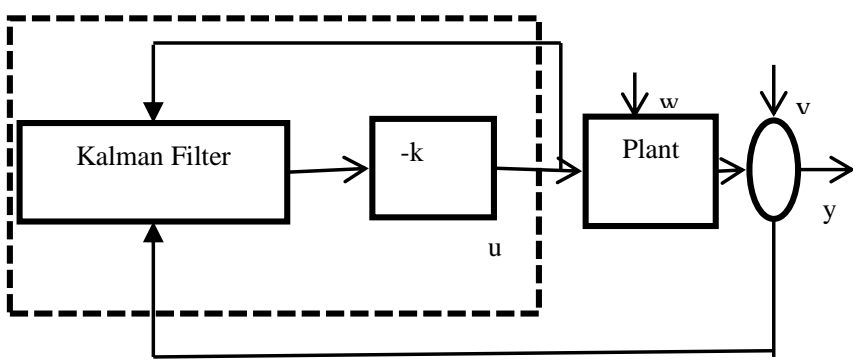

Fig. 3. Block diagram of DC motor with LQG

The mathematical representations for LQG are as follows. The cost function of LQG is given as $l(u)=\frac{1}{2} \int_{0}^{\infty}\left(x^{T}+2 x^{T} N u+u^{T} R u\right) d t \ldots . .3$

$\mathrm{N}$ is the trade-off between control effort and performance of regulation. Typically $\mathrm{N}$ value is 0 . The cost function $\mathrm{J}(\mathrm{u})$ is minimized by the state feedback $u(t)=-k x(t)$. Here the gain matrix $\mathrm{k}$ is solved algebraically using Riccati equation. The equation is

$A^{T} s+s A-(s B+N) R^{-1}\left(B^{T} s+N^{T}\right)+Q=0 . \ldots . .4$

In this equation, $\mathrm{s}$ is a matrix and $\mathrm{k}$ is obtained from $\mathrm{s}$. The equation is given as,

$K=R^{-1}\left(B^{T} s+N^{T}\right) \ldots \ldots .5$

The next step is the construction of the Kalman state estimator. $\widehat{X}$ is the kalman estimator which is determined from $\mathrm{u}=-\mathrm{k} \widehat{\bar{X}}$. The Kalman gain is obtained from the system model, DC motor, noise covariance data Q, R. where, $\mathrm{E}\left(\mathrm{ww} \mathrm{w}^{\mathrm{T}}\right)=\mathrm{Q}, \mathrm{E}\left(\mathrm{vv}^{\mathrm{T}}\right)=\mathrm{R}$.

The complete state space model for the plant ie DC motor is designed with LQG with Kalman filter and transient response of the plant is estimated and plotted and shown in Fig.4. The responses of the micro motor associated with insulin pump are plotted. The transient response is analysed for $t_{r}, t_{s}$, stability. The rise time is $0.691 \mathrm{sec}$ and the settling time is $1.23 \mathrm{sec}$ which is improved when compared with tuned PID controller used.

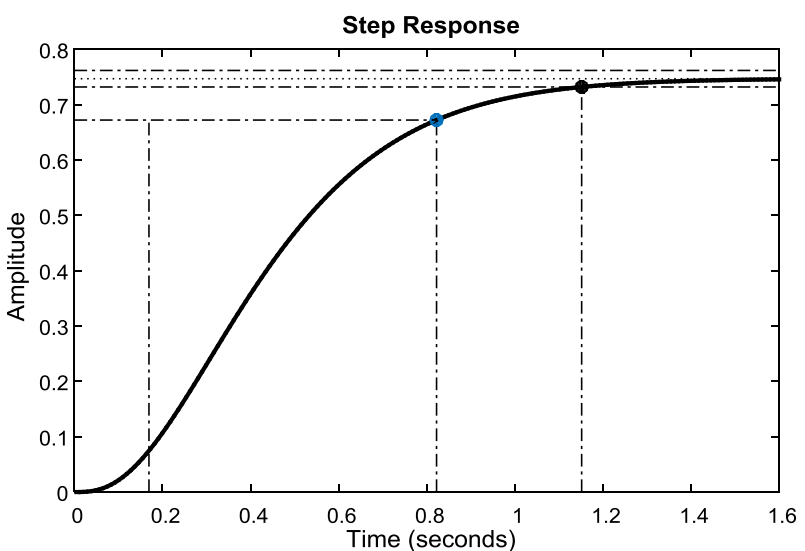

Fig. 4. Transient response of DC motor with LQG

\section{RESULT AND DISCUSSION}

In this paper, the PMDC motor 0615 employed for the infusion pump is considered to identify for its transient response. Two control strategies are employed. One is PID controller with Z-N tuning method and analysed for the rise time and settling time. Further the LQG technique is implemented to dc motor which has noise to find the rise time and settling time. The estimated state parameters are obtained from Kalman filter is shown in Fig.5. Based on the estimated values of rise time and settling time, the PMDC is regulated to get the required output. The estimated rise time is 0.59 seconds and the settling time is 1.05 seconds. For the infusion pumps, the PMDC should have quick rise time $t_{r}$ and settling time $t_{s}$, hence the LQG controller provides quick $t_{r}, t_{s}$ and effective robustness performances which result in practical feedback gain. The values obtained are tabulated in Table-I.

Table-I: Comparison of values

\begin{tabular}{|l|l|l|}
\hline $\begin{array}{l}\text { Control } \\
\text { Strategy }\end{array}$ & $\begin{array}{l}\text { Rise time } \\
\mathbf{t}_{\mathbf{r}} \text { in seconds }\end{array}$ & $\begin{array}{c}\text { Settling time } \\
\mathbf{t}_{\mathbf{s}} \text { in }\end{array}$ seconds \\
\hline PID & $3.37 \times 10^{5}$ & $5.99 \times 10^{5}$ \\
\hline LQG & 0.691 & 1.23 \\
\hline
\end{tabular}

\section{CONCLUSION}

For an infusion pump the drug has to be infused to the patient through catheter and a cannula. The PMDC helps insulin to release to the body in an optimal flow rate. The motor must be controlled in to achieve this precise operation as too much or too little drug is harmful to the patient. The motor incorporated in the pumping system should have optimum control with quick rise time and stability. To obtain these results LQG an optimum controller is implemented. The results are obtained with the prediction of $\mathrm{R}$ and $\mathrm{Q}$ values for the system according to the flow rate of the drug to be delivered to the patient.
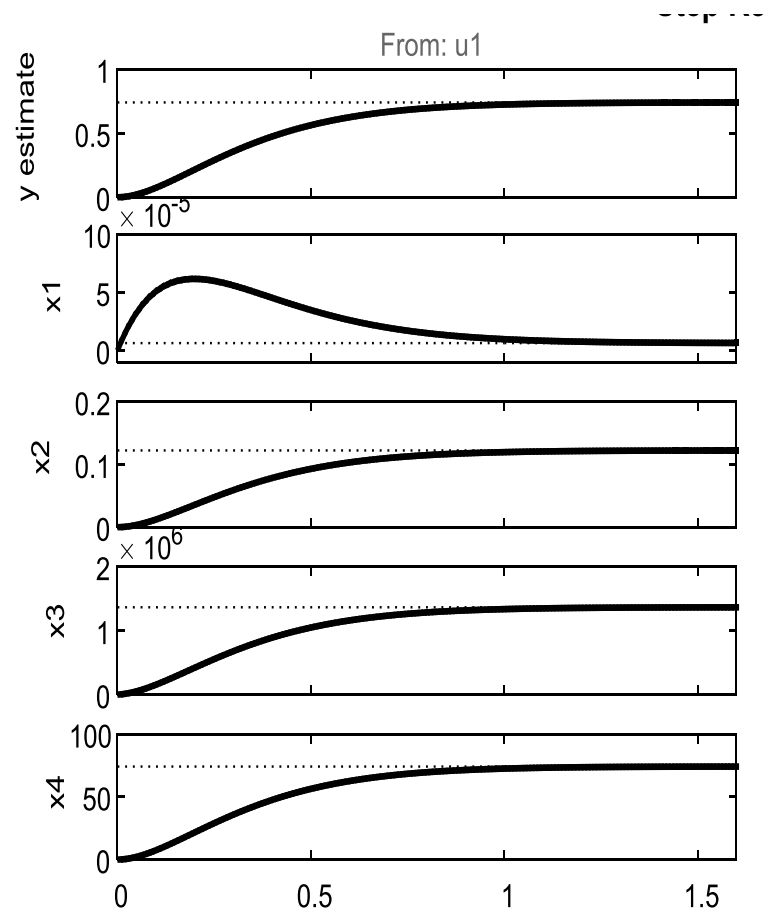

Fig. 5. Estimated responses

In this paper it is inferred that quick rise time, for 0615 motor series is reached with LQG when compared to the tuned PID controller for an infusion pump's motor which is needed for quick infusion of the fluid. 


\section{Examination of Control Parameters for Medical Grade Insulin Pump}

\section{REFERENCES}

[1] O. Vahidi, K. E. Kwok, R. B. Gopaluni, and F. K. Knop, "A comprehensive compartmental model of blood glucose regulation for healthy and type 2 diabetic subjects," Med. Biol. Eng. Comput., vol. 54, no. 9, pp. 1383-1398, 2016.

[2] P. Masci, R. Ruksėnas, P. Oladimeji, A. Cauchi, A. Gimblett, Y. Li, P. Curzon, and H. Thimbleby, "The benefits of formalising design guidelines: a case study on the predictability of drug infusion pumps," Innov. Syst. Softw. Eng., vol. 11, no. 2, pp. 73-93, 2015.

[3] M. Bozic, D. Todorovic, M. Petkovic, V. Zerbe, and G. S. Dordevic, "Advanced DC motor drive for haptic devices," Proc. Small Syst. Simul. Symp., vol. 16, no. 1, pp. 97-100, 2012.

[4] V. Iacovacci, L. Ricotti, P. Dario, and A. Menciassi, "Design and development of a mechatronic system for noninvasive refilling of implantable artificial pancreas," IEEE/ASME Trans. Mechatronics, vol. 20, no. 3, pp. 1160-1169, 2015.

[5] M. F. Moussa, M. Saad, and Y. G. Dessouky, "Adaptive control and one-line identification of sensorless Permanent Magnet DC motor," Proc. - 2010 IEEE Reg. 8 Int. Conf. Comput. Technol. Electr. Electron. Eng. Sib., pp. 852-857, 2010.

[6] M. Cescon and R. Johansson, "Linear Modeling and Prediction in Diabetes Physiology," pp. 187-222, 2014.

[7] S. Sankaranarayanan and G. Fainekos, "Simulating insulin infusion pump risks by in-silico modeling of the insulin-glucose regulatory system," Lect. Notes Comput. Sci. (including Subser. Lect. Notes Artif. Intell. Lect. Notes Bioinformatics), vol. 7605 LNBI, pp. 322-341, 2012.

[8] C. Pratthanaruk and J. Srisertpol, "A High Accuracy Speed Control of DC Motor Using Adaptive Torque Compensation on Lyapunov Stability with Kalman Filter," vol. 835, pp. 673-680, 2016.

[9] Y. L. Karnavas and I. D. Chasiotis, "PMDC coreless micro-motor parameters estimation through Grey Wolf Optimizer," Proc. - 2016 22nd Int. Conf. Electr. Mach. ICEM 2016, pp. 865-870, 2016.

[10] P. Zhao, Y. Chong, A. Zhao, and L. Lang, "A rapid infusion pump driven by micro electromagnetic linear actuation for pre-hospital intravenous fluid administration," no. January 2015, 2016.

[11] C. Paper and R. Kumar, "Kalman Filter for Speed Control of Dc Motor for Robotic Safety Critical Kalman Filter for Speed Control of Dc Motor for Robotic Safety Critical Applications,” no. May 2015, 2016.

[12] S. M. Khot and Y. Khan, "Simulation of Active Vibration Control of a Cantilever Beam using LQR , LQG and $\mathrm{H}-\infty$ Optimal Controllers," no. December, 2015.

[13] Faulhaber, "DC-Gearmotors Precious Metal Commutation with integrated Encoder 100 mNm Series 2619 ... SR ... IE2-16," Data Sheet, pp. 1-2, 2018.

[14] R. Akbari-Hasanjani, S. Javadi, and R. Sabbaghi-Nadooshan, "DC motor speed control by self-tuning fuzzy PID algorithm," Trans. Inst. Meas. Control, vol. 37, no. 2, pp. 164-176, 2015.

[15] P. L. Technology, "Study on the Speed Control Algorithm of DC Motor Based on the Software Phase-locked Loop Technology," Third Int. Conf. Intell. Networks Intell. Syst. Study, pp. 1-4, 2010.

[16] M. A. Aravind, N. Saikumar, and N. S. Dinesh, "Optimal Position Control of a DC Motor Using LQG with EKF," 2017 Int. Conf. Mech. Syst. Control Eng., no. 2, pp. 149-154, 2017.

\section{AUTHORS PROFILE}

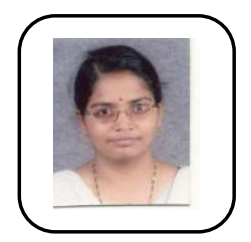

J. V. Alamelu*, Research scholar, SENSE, VIT, Chennai, Assistant Professor, Dept of EIE, MSRIT. Her areas of interests are on Data networks, sensors, physiological control systems, health care devices.

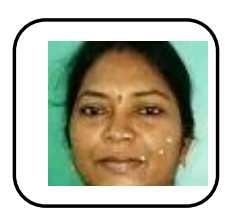

A. Mythili, Associate Professor, SENSE, VIT, Chennai. Her research interests are sensors, signals processing, Image processing in biomedical engineering. 